\title{
Examining Factors Contributing to Eritrea's Successful COVID-19 Response
}

\author{
Fikresus (Fikrejesus) Amahazion \\ College of Arts and Social Sciences Adi-Keih, Eritrea \\ Email: fikrejesus87@gmail.com
}

How to cite this paper: Amahazion, F. F. (2021). Examining Factors Contributing to Eritrea's Successful COVID-19 Response. Open Journal of Social Sciences, 9, 371-385. https://doi.org/10.4236/jss.2021.92025

Received: December 25, 2020

Accepted: February 21, 2021

Published: February 24, 2021

Copyright $\odot 2021$ by author(s) and Scientific Research Publishing Inc. This work is licensed under the Creative Commons Attribution International License (CC BY 4.0).

http://creativecommons.org/licenses/by/4.0/ (c) (i) Open Access

\begin{abstract}
The COVID-19 pandemic has been one of the greatest global crises in decades. To date, around the world tens of millions of cases have been confirmed, nearly two million people have died, and the livelihoods of billions have been greatly affected. While COVID-19 has been a truly global problem, infection and death rates in many African countries have been much lower than originally feared. One COVID-19 success story is Eritrea, a young, developing country in Northeast Africa that, by late December 2020, reported less than 1000 positive cases and one death due to COVID-19. However, despite its relative success, little focus has been devoted to Eritrea's response. How did it manage to keep COVID-19 at bay and what factors contributed to its success? Based on several different research methods, the present study finds that, notwithstanding limited resources, Eritrea has managed to respond to COVID-19 with relative efficiency and keep the virus at bay. The country's general success has been based upon a number of different factors.
\end{abstract}

\section{Keywords \\ Africa, Coronavirus, COVID-19, Eritrea, Health}

\section{Introduction}

Coronavirus disease (COVID-19) is an infectious disease caused by a newly discovered coronavirus. On 31 December 2019, Chinese media reported for the first time on an outbreak of viral pneumonia in the city of Wuhan. Months later, in early March 2020, COVID-19 was declared a pandemic by the World Health Organization (WHO). The pandemic has been one of the greatest global crises in decades; to date, tens of millions of cases have been confirmed in countries across the globe, more than one million people have died, and the livelihoods of billions have been greatly affected. 
While COVID-19 has been a truly global problem, respecting no boundaries, infection and death rates in many African countries have been much lower than initially feared. Many countries in Africa experienced an exponential growth in cases much later than countries in other regions and had consistently confirmed fewer cases per capita. The case-fatality ratio (CFR) for COVID-19 in Africa is lower than many other parts of the world (such as Europe and North America), suggesting that disease outcomes have been less severe among African populations (PERC, 2020). Although Africa as a continent has broadly been successful since the first reported case in mid-February 2020, individual countries within the region have reported COVID-19 epidemics of vastly different intensities and responded to the disease with varying levels of success. One country that has had relative success against COVID-19 is Eritrea, a young, low-income country in Northeast Africa. As of late December, it reported a total of 951 positive cases and one death due to COVID-19.

However, despite Eritrea's relative success and much attention has been focused on the situation around the world, including other parts of Africa, no research or other work has been devoted to Eritrea. How did it manage to keep COVID-19 at bay and what factors contributed to its relative success? Using a variety of methods, the current study, the only analysis of COVID-19 in the country, identifies important aspects of the country's response to the virus. The present study provides useful insights, facilitates and enriches cross-country learning and sharing of best practices, and contributes to cumulative understanding of salient factors in successful responses.

In the next section, the methods are outlined. Then, Eritrea's geopolitical context is reviewed, followed by an outline of the general healthcare system. Subsequently, the trend of COVID-19 in the country is presented, before a discussion of the important factors contributing to Eritrea's successful response. The final section concludes and briefly outlines some areas for future research.

\section{Methods}

The present study relied on several methods. In-depth, semi-structured interviews were conducted with key informants across Eritrea. Participants were selected through targeted, convenience, and snowball sampling techniques. Key informants were from several national institutions and government ministries, with understanding, knowledge, information, and perspective about the country and its response.

Interviews were open-ended and semi-structured (Hammer \& Wildavsky, 1989), a particularly useful format since the study retained many exploratory features. Furthermore, open-ended questions offered respondents an opportunity to organize responses within their own framework, thus, potentially increasing the validity of responses. While the interviews and questions were semi-structured, they involved many follow-up queries and creative locutions (e.g., "why" and "what else") in order to further probe issues of merit or pursue 
clarity (Hammer \& Wildavsky, 1989).

All interviews began after obtaining verbal consent and were generally conducted in person or by telephone. Conversations lasted between one and two hours and were conducted in either Tigrinya or English, which are two of Eritrea's three national working languages. During all interviews, hand-written notes were taken, with transcription conducted shortly afterward, often the same day, in order to reduce errors and ensure a high degree of accuracy and detail (Newing, 2011).

Additionally, the current study is guided by numerous informal conversations and small group discussions with various locals and employees, and a review of literature, data, and materials collected from an assortment of sources, such as local offices (e.g., Ministry of Information, etc.), non-governmental organizations, government ministries, and regional or global organizations (e.g., the United Nations Development Programme and the WHO).

Data analysis is based on data triangulation: obtaining, comparing, and contrasting evidence from a wide range of data sources (Bieri, 2010; Creswell \& Miller, 2000; Yin, 2003). Relying on multiple sources of data allows for the convergence of various lines of inquiry, strengthens validity (Creswell \& Miller, 2000; Yin, 2003), and is important in gaining cumulative insights and acquiring a broader, richer perspective of remittances in the context of Eritrea.

\section{Results}

\subsection{Geopolitical Background}

After waging one of Africa's longest and most destructive liberation wars of the 1900s, Eritrea gained independence in 1991. Eritrea has an area of approximately 124,000 square kilometers, and is divided into six main political administrative regions (See Figure 1). The country has a population of approximately 3.5 million people, which is distributed between nine separate ethno-linguistic groups, and its per-capita gross domestic product is approximately $\$$ US 780 . The population is split almost evenly between Christianity and Islam, with each representing nearly half of the population (EPHS, 2010; IMF, 2016; World Bank, 2018).

Despite relatively modest resources, Eritrea is one of the few countries that entered the United Nations Sustainable Development Goals period having achieved most of the Millennium Development Goals targets on health. Some of its significant results within the health sector include: life expectancy has increased; maternal, infant and child mortality rates have reduced dramatically; immunization coverage has rocketed; malaria mortality and morbidity have plummeted; and human immunodeficiency virus prevalence has decreased considerably (Ministry of Health \& UNDP, 2014; Pose \& Samuels, 2011; UN Eritrea, 2017; WHO, 2017). Although these developments reflect considerable progress, the country continues to face a variety of significant issues, including regional conflict and instability, poverty reduction, socio-political challenges, erratic rainfall and the potential for severe drought, infrastructure development, food 


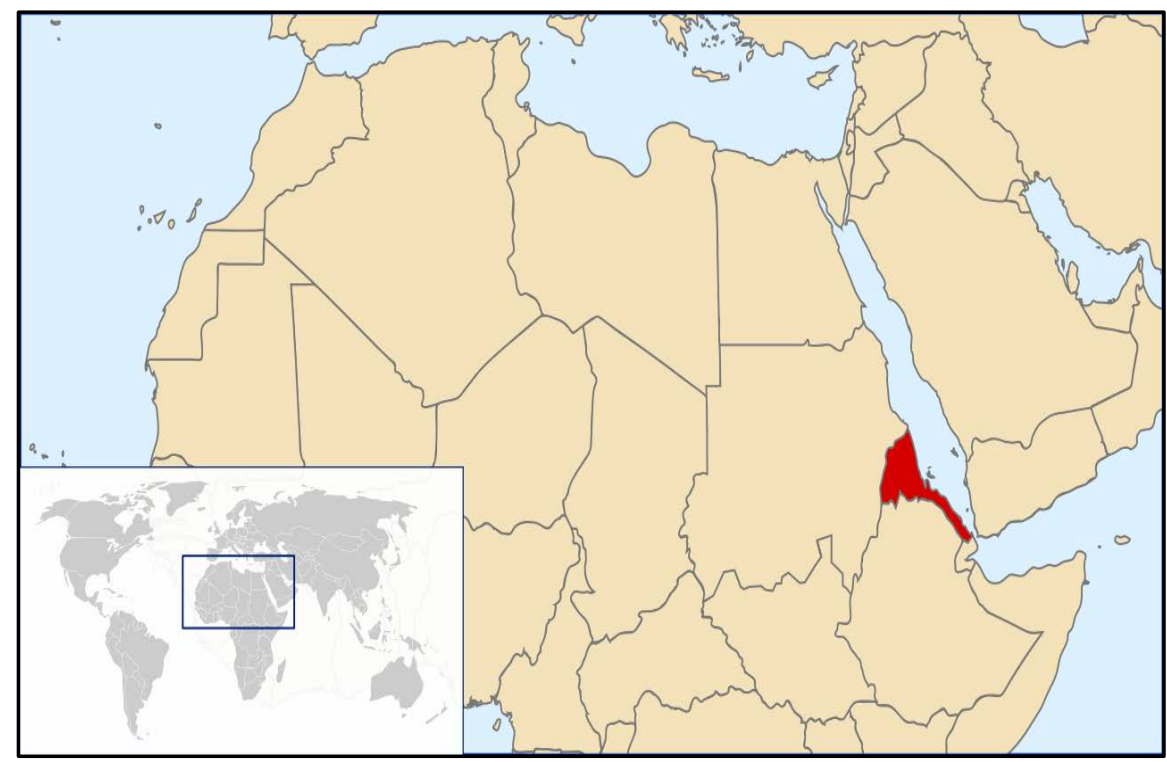

Figure 1. Eritrea geographic setting. Image credit: https://commons.wikimedia.org/wiki/File:LocationEritrea.svg.

security, a shortage of skilled labor, and macroeconomic imbalances (AfDB, 2016; EPHS, 2010; IMF, 2003; Ministry of Health \& UNDP, 2014; Pose \& Samuels, 2011; UN Eritrea, 2017; World Bank, 2018).

\subsection{General Healthcare Structure}

Eritrea's national health policy aims to ensure equity and access to essential health services at an affordable cost. Priorities include public health fundamentals, such as clean water, sanitation, and vaccination, addressing maternal and child health issues, and the control of communicable diseases. Health services are delivered utilizing a referral system based on three tiers, comprising primary-level facilities (health stations and health centres), secondary-level facilities (first contact or sub-zone hospitals and zonal referral hospitals) and tertiary-level facilities (national referral hospitals). While there are no private health facilities operating in the country, there is a system of private practice within government health facilities by way of a partnership between the Government and health workers (Amahazion, 2018: 707; Ministry of Health, 2005; Pose \& Samuels, 2011; WHO, 2017).

As with many other low-income countries, Eritrea faces numerous challenges within its healthcare system. The country has deficits in health financing, access to basic technologies, medicines, and medical information systems, while lacking a skilled health workforce necessary for combating noncommunicable diseases. Furthermore, healthcare workers often have a heavy workload related to a low doctor to patient ratio (which, at approximately 0.5 per 10,000 people, is slightly less than the average for Sub-Saharan Africa). There are also constraints with few intensive care unit beds and a relatively low number of specialized intensive care nurses. Considerable investments including educating and training physi- 
cians and medical staff through establishing medical, dental, and health sciences facilities and schools, developing linkages with foreign partners, and expanding access to foreign scholarships and distance learning are currently being made. Notably, Eritrea also has dedicated and committed staff in primary healthcare (Amahazion, 2018: p. 707-708; Mendis et al., 2012).

\subsection{COVID-19 in Eritrea}

Eritrea reported its first coronavirus case on 21 March, a 39-year old Eritrean national arriving from Europe, making it one of the last countries on the continent to have a confirmed case. Over the following several weeks, the case count slowly rose, reaching 39 by 8 May. All those infected eventually fully recovered and on 15 May Eritrea declared it was virus-free with no active cases in the country. Shortly after, a large-scale random testing program was begun in Asmara, the capital (from 17 May until 2 June). Using random sampling procedures, 4659 households or $15 \%$ of residents were covered, with one household representative undergoing the nasal and throat swab tests. Test results revealed only one positive case out of 4659 tests (about $0.02 \%$ ). As the testing program slowly expanded, moving from the capital to other parts of the country, the number of positive cases rose, growing to 203 by the end of June. By mid-October, there were 414 positive cases from 41,100 tests, illustrating a low positivity rate. With tests continuing, the total positive case count reached 951 on 24 December (See Figure 2, Figure 3).

The vast majority of positive cases have been imported (i.e., nationals returning from abroad), while local transmission has been effectively contained. With an early and extended ban on commercial flights, points of entry have been the long land and sea borders of the country with Sudan, Ethiopia, Djibouti, and Yemen. Numerous testing and quarantine centers, approximately 100 in all, were established along or in the near vicinity of these entry points. This has been bolstered by testing and tracing in surrounding border towns and villages to gauge the rate of potential transmission of the pandemic.

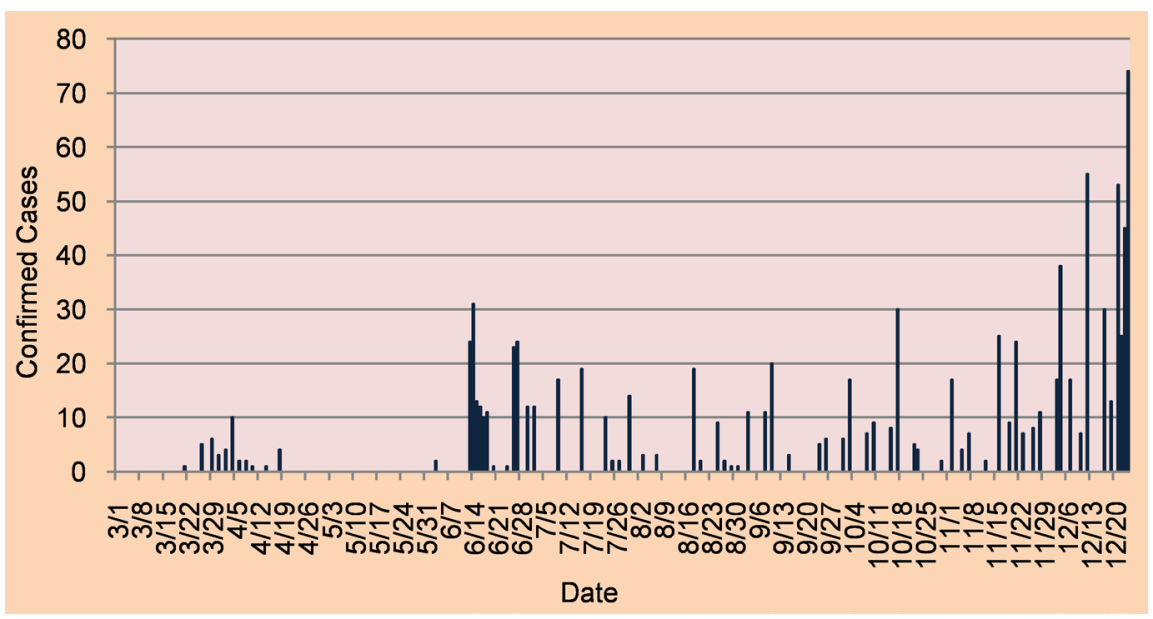

Figure 2. Eritrea COVID-19 daily confirmed cases. 
To date, the severity of the positive cases has remained invariably mild for all patients. The median period of hospitalization remains at 21 days, and the country has demonstrated an impressive recovery rate. In particular, the number of recovered cases has been higher than active cases; out of 951 confirmed cases to-date, 600 patients have recovered fully, while there has been one death (CFR $=0.105)$. These are all comparatively much lower than the regional or global averages (WHO, 2020). Notably, there has not been an overall rise in mortality or excess deaths in the country, indicating that Eritrea's comparatively low COVID-19 cases and deaths are not the result of a lack of testing, misdiagnoses, or missing cases (See Figure 4).

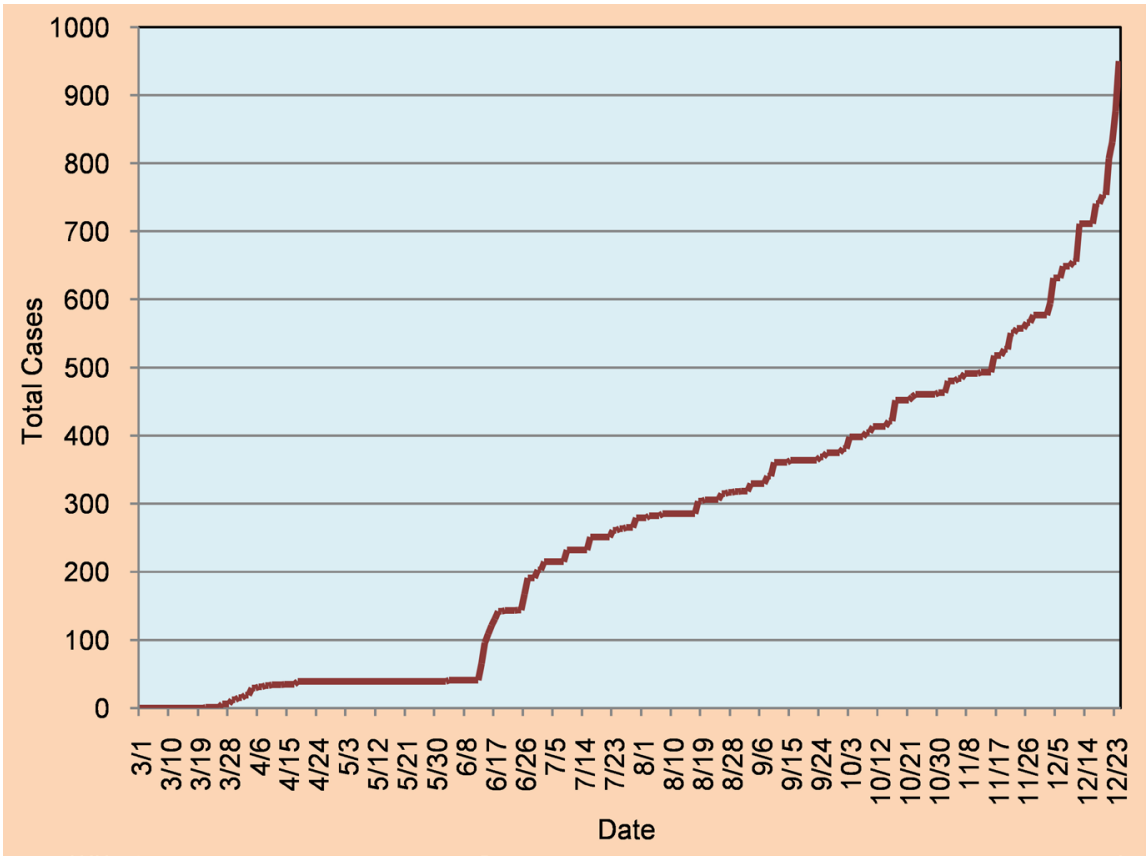

Figure 3. Eritrea COVID-19 cumulative total cases.

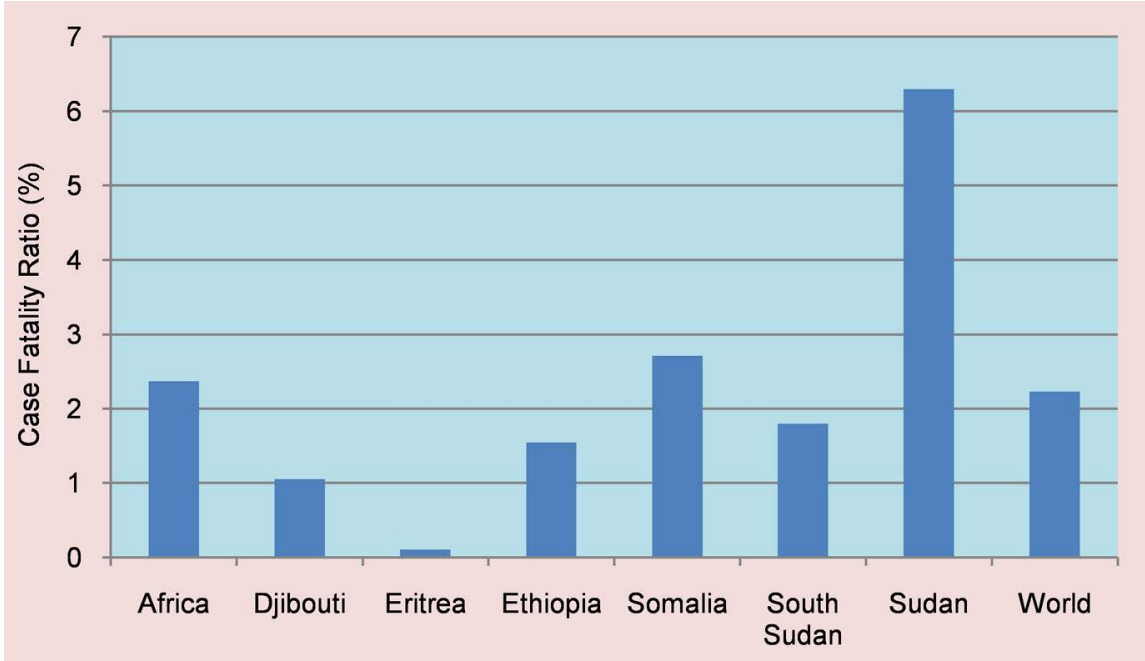

Figure 4. Horn of Africa COVID-19 case fatality ratio. 


\subsection{Factors Contributing to Eritrea's Response}

Eritrea's relative success in containing COVID-19 is rooted in several different factors.

\subsubsection{Swift Action and Decisive Leadership}

Decisive leadership is a key factor in determining success against COVID-19 (Al Saidi et al., 2020). In addition, strong, swift action, guided by sound science-driven advice, public health fundamentals, and evolving evidence, is also vital. Research suggests that denial and even brief delay or hesitation (such as just a few days) made a considerable difference in the spread of COVID-19 in many countries around the world (Gibney, 2020; Redlener, Sachs, Hansen, \& Hupert, 2020).

In Eritrea, strong, aggressive action was taken quickly, based on a clear recognition and understanding that a large outbreak would overwhelm the healthcare system and have a devastating exponential impact on the country, particularly on its vulnerable population, including the poor, the elderly, and those with co-morbidities. Prior to the first confirmed case, a national taskforce was established, comprising government high-level officials, health authorities, and experts, to lead the country's response to the pandemic. In collaboration with UNICEF, the WHO, and other international organizations, a National Preparedness and Response Plan was developed and proactive steps were taken to strengthen the healthcare system.

On March 11, ten days before the country's first confirmed positive case, the government released a statement outlining the global dimensions of COVID-19 and urging people to avoid all foreign or domestic travel, except for essential or emergency purposes. Screening at airports was introduced, with all arrivals from China, Italy, Iran and South Korea, then with high and rapidly increasing caseloads, placed into mandatory quarantine. Days later (16 March), all internal and external travel was restricted and calls were made to avoid large public gatherings, followed by the Ministry of Health $(\mathrm{MoH})$ releasing a statement on 21 March (the date of first case), calling for citizens to take utmost precautionary measures to prevent the spread of the pandemic and to follow national guidelines. Public health measures were also being strongly encouraged, including avoiding handshakes, frequent hand-washing, social distancing, and wearing of face masks.

Two days after the first confirmed case, more guidelines were announced: social gatherings of more than 10 people were prohibited, while cinemas, nightclubs, and places of worship were closed. Establishments remaining open (such as bars, cafés, and restaurants, pharmacies) were to enforce strict safety measures (i.e., social distancing, facemasks, sanitizers, etc.). Then on March 25 all commercial flights into and out of the country were suspended, and borders were closed allowing only cargo, freight, and the expatriation of foreign nationals. This was quickly followed by the closing of all learning institutions, the shutting down of all public and private transport and prohibition of intercity travel, and the closure of bars, restaurants, and cafés. 
A total nationwide lockdown was eventually declared the following week (2 April, initially to last for 21 days, the lockdown was extended longer). The lockdown, among the most stringent in the world (Hale, Webster, Petherick, Phillips, \& Kira, 2020), prohibited all non-essential movement outside homes. Exemptions were made for several sectors, allowing operations to continue with reduced hours and strict compliance with standard preventive measures (e.g., fisheries, household and commercial farms, banking and financial services, food supply chains, freight trucks, and vital transportation).

The government also engaged with partners and suppliers very quickly to procure health equipment and supplies, including the delivery of 84 oxygen concentrators, additional personal protective equipment, and other critical medical supplies. As well, bottlenecks to transport and supplies were identified, and alternative channels of supply and production were developed. Local factories, in collaboration with the $\mathrm{MoH}$, shifted production to manufacture hand sanitizer, soaps, and facemasks, and these products were quickly distributed to health facilities, offices and ministries, schools, and vulnerable populations across the country.

\subsubsection{Past Experience and Late Emergence of Virus}

Another important factor was that Eritrea was able to draw upon its own extensive experience fighting disease. Since gaining independence in 1991, the country has accumulated considerable experience and achieved significant success in controlling endemic and communicable diseases, such as malaria, meningitis, measles, rubella, tuberculosis, HIV, hepatitis, and polio. This provided useful lessons and technical know-how, as well as helped strengthen the resilience of the general healthcare system.

The delayed arrival of the virus into the country was also significant, allowing officials and authorities to better understand the threats posed by COVID-19, as well as extract valuable insights or observations from what other countries were doing to successfully combat the virus. The late emergence of COVID-19 in Eritrea also afforded critical time to prepare and mobilize a national-level response.

\subsubsection{Clear Communication and Public Buy-In}

Eritrea's response has been characterized by clear, consistent, and frequent communication, as well as local buy-in and adherence. Clear, consistent, and frequent communication can facilitate public health interventions and support or adherence of local groups. Work has shown that people's understanding of their personal risk affects how likely they are to support, engage in, and adhere to preventive behaviors (Bradley, Mansouri, Kee, \& Garcia, 2020; Brewer et al., 2007; Holmes, 2008; Vaughan \& Tinker, 2009). In addition to helping ensure that the population is able to understand the magnitude of the problem and rationale behind various preventive measures, clear communication dispels rumors and false or misleading information, and can reduce public anxiety, fear, or panic. 
From the outset, Eritrea's MoH, Ministry of Education, Ministry of Information, and the high-level national taskforce provided clear, detailed updates on a regular, often daily, basis. Importantly, with Eritrea being an ethnically diverse, multilingual country, public service messages and information about COVID-19 were developed and translated into all nine local languages (as well as sign language) and regularly disseminated through various forms of media (national television and radio). Safety, prevention, and hygiene guidelines were also delivered through short message services for mobile telephones, and three " $24 / 7$ " toll-free hotlines were established to provide information on health, hygiene, and prevention, and to report symptoms. Additionally, information posters and pamphlets were displayed in pharmacies, health clinics, shopping areas, on billboards and notice boards, and within other public spaces. Safety messages and themes were also integrated into popular television and radio entertainment programs, while leading artists recorded songs, videos, and public messages encouraging support for the national campaign against COVID-19.

Communication has been allied with public buy-in. A large body of literature has demonstrated the importance of public buy-in (which involves the trust, acceptance, and support of local residents) to the success, survival, and effectiveness of community projects and public health interventions (Kahn et al., 2002; Maibach \& Holtgrave, 1995; Poulsen, Spiker, \& Winch, 2014). In Eritrea, buy-in has increased trust, reduced community resistance or reticence, and encouraged compliance with national policies and various public health and safety guidance. In many areas, local volunteers and neighborhood committees supported monitoring of adherence to guidelines. The unfortunate social unrest, dysfunction, violence, and coercion, heavy-handedness, or abuse by authorities witnessed in some countries has not been apparent in Eritrea.

Community elders and religious leaders were engaged to strengthen buy-in and help facilitate the dissemination of updates and information. These figures are key influencers, regarded as credible sources of information, and command high respect. They regularly made community announcements and delivered messages via media. Buy-in was also strengthened by a range of government actions and initiatives, such as uninterrupted payment of salaries to all civil service and parastatal employees, waiving or deferring collection of various fees (e.g., electricity, water, telephone, etc.), ensuring the availability of and fair prices for different goods and services, cancelling evictions, compensating those who lost income from work stoppages, and extending loans, cash handouts, food, and basic essential items to vulnerable individuals, families, and businesses. These initiatives were buttressed by a national fundraising campaign that involved financial and material contributions from individuals (local and living abroad), businesses, religious institutions, associations, and cooperatives.

\subsubsection{Low Global Interconnectivity}

Research has shown that international air traffic was a major facilitator in the early international distribution of COVID-19 and contributed to the importa- 
tion of cases from highly infected countries. For instance, research by Lau et al. (2020) found that the number of flight routes as well as total passenger volume was a highly relevant risk factor for the spread of COVID-19 (Lau et al., 2020). While multiple regions within Asia, as well as some in North America and Europe were at serious risk of constant exposure to COVID-19 from China and other highly infected countries, risk for COVID-19 exposure remained relatively low in South America and Africa (Lau et al., 2020). Similarly, in a study of 34 mostly European countries reporting international flights to 154 destination countries, Keita (2020) finds that more connected countries registered first infection cases significantly earlier than less connected countries and that travel restrictions could be key in slowing down the spread of infections (Keita, 2020).

Importantly, Eritrea is relatively less connected than many other countries in the world. It has a relatively low volume of international air travel, and few direct links to highly infected countries (e.g., China), meaning it was relatively insulated from a high risk of importation of cases. Notably, a modeling study conducted by Gilbert et al. (2020) exploring the vulnerability of African countries against importations of COVID-19 suggests Eritrea had a low importation risk based on its low volume of air travel departing from airports in the infected provinces in China (Gilbert et al., 2020).

\subsubsection{Demographic Structure}

The demographic structure of the population in Eritrea has also played a role in containing the spread of COVID-19 in the country. Globally, children and adolescents are at a much lower risk of symptomatic COVID-19 than any other age group. To date, most of those who have died due to COVID-19 have been adults and older population groups. While the virus can certainly infect and kill children and young people, they tend to suffer much milder symptoms from COVID-19 compared to older populations and there are very few severe cases and deaths from the virus among children and adolescents (Snape \& Viner, 2020; Starke et al., 2020; Wang et al., 2020).

In Eritrea, the fertility rate remains relatively high and as with other countries in Africa a large percentage of the population is adolescents and youth. Thus, this could be an important contributing factor to the low number of reported cases of infections and deaths due to COVID-19 in the country.

Additionally, Eritrea does not have specialized nursing homes or long-term care facilities for older people. These have been key locations for infections and deaths in many other regions, particularly in countries across Europe and North America. Older persons living in nursing homes and long-term care facilities have a higher risk for infection and adverse outcomes from the disease because they live in close proximity to others (Danis et al., 2020; Dichter, Sander, Seismann-Petersen, \& Köpke, 2020; Pitkälä, 2020; Stern \& Klein, 2020). However, in Eritrea, extended families, communities, and religious groups traditionally provide long-term care for the elderly within the home. As well, many elderly live in rural areas, where there is less connectivity with urban or metropolitan areas 
which tend to have higher infection and higher mortality rates (Hamidi, Sabouri, \& Ewing, 2020).

Other important risk factors for serious illness and death from COVID-19, such as obesity, high blood pressure, heart disease, lung disease, cancer, and diabetes, although slowly increasing in recent years, are generally less prevalent in Eritrea (Amahazion, 2018; Mufunda et al., 2006; Usman et al., 2006).

\section{Conclusion}

The COVID-19 pandemic has been one of the greatest global crises in decades. Since its emergence in late 2019, countries around the world have responded to the disease with varying levels of success. Despite limited resources, Eritrea has managed to handle the pandemic with relative efficiency and keep COVID-19 at bay. The country's general success against the virus has been based on a number of different factors.

Strong, aggressive, and quick action helped prevent spread and bought critical time to prepare the health system, while systematic screening, tracing, isolation, and social distancing measures were important in severing local transmission. Clear, consistent, and frequent communication from the government and health authorities increased public understanding and dispelled potential misinformation, while public buy-in contributed to adherence with guidelines and safety measures. Eritrea's lockdown, coming early and among the most stringent in the world, was also significant, as it bought critical time to prepare, limited transmission, flattened any potential COVID-19 curve, and prevented deaths, while ultimately ensuring that the healthcare system was not overwhelmed.

Of note, the country's extensive past experiences and successes in controlling endemic and communicable diseases provided important lessons and strengthened the resilience of the healthcare system. Furthermore, the delayed arrival of the virus into Eritrea provided an opportunity to better understand the threats posed by COVID-19, extract valuable insights from other countries, and prepare a national-level response. Last, Eritrea's relatively low connectivity insulated it from a high risk of importation, while the demographic structure of the population meant that many were at reduced risk of severe cases.

Although the present study sheds light on important aspects of Eritrea's generally successful response to COVID-19, several topics merit further research and analysis. For instance, an important component of Eritrea's strict national lockdown was the closure of educational institutions. Although educational programs have been offered on national television, seeking to ensure learning continues with minimum disruption, this is not the same as attending in person, while some regions or households may lack access to media or digital tools. Accordingly, future research can investigate whether and in what ways the extended lockdown impacted the important educational progress and gains in education across country, particularly for poor or vulnerable individuals and households. Moreover, future work can examine the effect of the COVID-19 
pandemic and extended lockdown on mental health in the country, a topic that has received growing global attention during the pandemic and which has traditionally been understudied in Eritrea.

\section{Funding}

There are no sources of funding to declare.

\section{Human Participant Protection}

No protocol approval was required because no research involving human participants was conducted.

\section{Conflicts of Interest}

The author declares no conflicts of interest regarding the publication of this paper.

\section{References}

AfDB (2016). African Economic Outlook: Sustainable Cities and Structural Transformation. Abidjan, Ivory Coast: African Development Bank Group.

Al Saidi, A. M. O., Nur, F. A., Al-Mandhari, A. S., El Rabbat, M., Hafeez, A., \& Abubakar, A. (2020). Decisive Leadership Is a Necessity in the COVID-19 Response. The Lancet, 396, 295-298. https://doi.org/10.1016/S0140-6736(20)31493-8

Amahazion, F. (2018). Renal Replacement Therapy in Eritrea. Transplantation, 102, 707-710. https://doi.org/10.1097/TP.0000000000002152

Bieri, F. (2010). From Blood Diamonds to the Kimberley Process: How NGOs Cleaned up the Global Diamond Industry. Burlington, VT: Ashgate Publishing Limited.

Bradley, D. T., Mansouri, M. A., Kee, F., \& Garcia, L. M. T. (2020). A Systems Approach to Preventing and Responding to COVID-19. E-Clinical Medicine, 21, Article ID: 100325.

Brewer, N. T., Chapman, G., Gibbons, F. X., Gerrard, M., McCaul, K. D., \& Weinstein, N. D. (2007). Meta-Analysis of the Relationship Between Risk Perception and Health Behavior: The Example of Vaccination. Health Psychology, 26, 136-145.

https://doi.org/10.1037/0278-6133.26.2.136

Creswell, J., \& Miller, D. (2000). Determining Validity in Qualitative Inquiry. Theory into Practice, 39, 124-130. https://doi.org/10.1207/s15430421tip3903 2

Danis, K., Fonteneau, L., Georges, S., Daniau, C., Bernard-Stoecklin, S., Domegan, L., O'Donnell, J., Hauge, S. H., Dequeker, S., Vandael, E., Van der Heyden, J., Renard, F., Sierra, N. B., Ricchizzi, E., Schweickert, B., Schmidt, N., Abu, S. M., Eckmanns, T., Paiva, J., \& Schneider, E. (2020). High Impact of COVID-19 in Long-Term Care Facilities, Suggestion for Monitoring in the EU/EEA, May 2020. Eurosurveillance, 25, Article ID: 2000956.

Dichter, M. N., Sander, M., Seismann-Petersen, S., \& Köpke, S. (2020). COVID-19: It Is Time to Balance Infection Management and Person-Centered Care to Maintain Mental Health of People Living in German Nursing Homes. International Psychogeriatrics, 32, 1157-1160. https://doi.org/10.1017/S1041610220000897

EPHS (2010). Eritrea: Population and Health Survey, 2010. Asmara, Eritrea: Eritrea National Statistics Office. 
Gibney, E. (2020). Whose Coronavirus Strategy Worked Best? Scientists Hunt Most Effective Policies. Nature, 581, 15-16. https://doi.org/10.1038/d41586-020-01248-1

Gilbert, M., Pullano, G., Pinotti, F., Valdano, E., Poletto, C., Boëlle, P., D’Ortenzio, E., Yazdanpanah, Y., Eholie, S. Y., Altmann, M., Gutierrez, B., Kraemer, M. U. G., \& Colizza, V. (2020). Preparedness and Vulnerability of African Countries against Importations of COVID-19: A Modelling Study. The Lancet, 395, 871-877.

https://doi.org/10.1016/S0140-6736(20)30411-6

Hale, T. Webster, S., Petherick, A., Phillips, T., \& Kira, B. (2020). Oxford COVID-19 Government Response Tracker. Oxford: Blavatnik School of Government.

https://www.bsg.ox.ac.uk/research/research-projects/coronavirus-government-respons e-tracker

Hamidi, S., Sabouri, S., \& Ewing, R. (2020). Does Density Aggravate the COVID-19 Pandemic? Early Findings and Lessons for Planners. Journal of the American Planning Association, 86, 495-509. https://doi.org/10.1080/01944363.2020.1777891

Hammer, D., \& Wildavsky, A. (1989). The Open-Ended, Semi-Structured Interview: An (Almost) Operational Guide. In A. Wildavsky (Ed.), Craftways: On the Organization of Scholarly Work (pp. 57-101). New Brunswick, NJ: Transaction Publishers.

Holmes, B. J. (2008). Communicating about Emerging Infectious Disease: The Importance of Research. Health, Risk and Society, 10, 349-360.

https://doi.org/10.1080/13698570802166431

IMF (2003). Eritrea: Selected Issues and Statistical Appendix. IMF Country Report No. 03/166, Washington DC: International Monetary Fund (IMF).

IMF (2016). World Economic Outlook Database: April 2016. Washington DC: International Monetary Fund (IMF). http://www.imf.org/external/data.htm

Kahn, E. B., Ramsey, L. T., Brownson, R. C., Heath, G. W., Howze, E. H., Powell, K. E., Stone, E. J., Rajab, M. W., \& Corso, P. (2002). The Effectiveness of Interventions to Increase Physical Activity: A Systematic Review. American Journal of Preventive Medicine, 22, 73-107. https://doi.org/10.1016/S0749-3797(02)00434-8

Keita, S. (2020). Air Passenger Mobility, Travel Restrictions, and the Transmission of the Covid-19 Pandemic between Countries. Center for Economic Policy Research, 9, 77-96.

Lau, H., Khosrawipour, V., Kocbach, P., Mikolajczyk, A., Ichii, H., Zacharski, M., Bania, J., \& Khosrawipour, T. (2020). The Association between International and Domestic Air Traffic and the Coronavirus (COVID-19) Outbreak. Journal of Microbiology, Immunology and Infection, 53, 467-472. https://doi.org/10.1016/j.jmii.2020.03.026

Maibach, E., \& Holtgrave, D. R. (1995). Advances in Public Health Communication. Annual Review of Public Health, 16, 219-238.

https://doi.org/10.1146/annurev.pu.16.050195.001251

Mendis, S., Al Bashir, I., Dissanayake, L., Varghese, C., Fadhil, I., Marhe, E., Sambo, B., Mehta, F., Elsayad, H., Sow, I., Algoe, M., Tennakoon, H., Truong, L. D., Lan, L. T. T., Huiuinato, D., Hewageegana, N., Fahal, N. A. W., Mebrhatu, G., Tshering, G., \& Chestnov, O. (2012). Gaps in Capacity in Primary Care in Low-Resource Settings for Implementation of Essential Noncommunicable Disease Interventions. International Journal of Hypertension, 2012, Article: ID 584041. https://doi.org/10.1155/2012/584041

Ministry of Health (2005). Human Resources Strategy for the Health Sector in Eritrea: 2006-2010. Asmara, Eritrea: Research and Human Resources Development Department, Ministry of Health.

Ministry of Health and UNDP (2014). Health Millennium Development Goals Report: Innovations Driving Health MDGs in Eritrea. Asmara, Eritrea: Ministry of Health and United Nations Development Programme. 
Mufunda, J., Mebrahtu, G., Usman, A., Nyarango, P., Kosia, A., Ghebrat, Y., Ogbamariam, A., Masjuan, M., \& Gebremichael, A. (2006). The Prevalence of Hypertension and Its Relationship with Obesity: Results From a National Blood Pressure Survey in Eritrea. Journal of Human Hypertension, 20, 59-65.

https://doi.org/10.1038/sj.jhh.1001924

Newing, H. (2011). Qualitative Interviews and Focus Groups. In H. Newing (Ed.), Conducting Research in Conservation: Social Science Methods and Practice (pp. 125-143). New York, NY: Routledge.

PERC (2020). Responding to COVID-19 in Africa: Using Data to Find a Balance (Part II). Partnership for Evidence-Based Response to COVID-19 (PERC).

Pitkälä, K. H. (2020). COVID-19 Has Hit Nursing Homes Hard. European Geriatric Medicine, 11, 889-891.

Pose, R. R., \& Samuels, F. (2011). Progress in Health in Eritrea: Cost-Effective Inter-Sectoral Interventions and a Long-Term Perspective. London, UK: Overseas Development Institute.

Poulsen, M. N., Spiker, M. L., \& Winch, P. J. (2014). Conceptualizing Community Buy-In and Its Application to Urban Farming. Journal of Agriculture, Food Systems, and Community Development, 5, 161-178. https://doi.org/10.5304/jafscd.2014.051.014

Redlener, I., Sachs, J. D., Hansen, S., \& Hupert, N. (2020). 130,000-210,000 Avoidable COVID-19 Deaths-And Counting-In the U.S. New York: Earth Institute, Columbia University.

Snape, M. D., \& Viner, R. M. (2020). COVID-19 in Children and Young People. Science, 370, 286-288. https://doi.org/10.1126/science.abd6165

Starke, K. R., Petereit-Haack, G., Schubert, M., Kämpf, D., Schliebner, A., Hegewald, J., \& Seidler, A. (2020). The Age-Related Risk of Severe Outcomes Due to COVID-19 Infection: A Rapid Review, Meta-Analysis, and Meta-Regression. International Journal of Environmental Research and Public Health, 17, 5974-5983. https://doi.org/10.3390/ijerph17165974

Stern, C., \& Klein, D. B. (2020). Stockholm City's Elderly Care and Covid19: Interview with Barbro Karlsson. Society, 57, 434-445.

UN Eritrea (2017). Delivering as One for the SDGs: The Strategic Partnership Cooperation Framework (SPCF) between the Government of the State of Eritrea and the United Nations. Asmara, Eritrea: Eritrea Ministry of National Development and United Nation Eritrea Office.

Usman, A., Mebrahtu, G., Mufunda, J., Nyarang'o, P., Hagos, G., Kosia, A., Ghebrat, Y., Mosazghi, A., Atanga, S. J., \& Equbamichael, M. M. (2006). Prevalence of Non-Communicable Disease Risk Factors in Eritrea. Ethnicity and Disease, 16, 542-546.

Vaughan, E., \& Tinker, T. (2009). Effective Health Risk Communication About Pandemic Influenza for Vulnerable Populations. American Journal of Public Health, 99, S324-S332. https://doi.org/10.2105/AJPH.2009.162537

Wang, D., Hu, B., Hu, C., Zhu, F., Liu, X., Zhang, J., Wang, B., Xiang, H., Cheng, Z., Xiong, Y., Zhao, Y., Li, Y., \& Wang, X. (2020). Clinical Characteristics of 138 Hospitalised Patients with 2019 Novel Coronavirus-Infected Pneumonia in Wuhan, China. Journal of the American Medical Association, 323, 1061-1069. https://doi.org/10.1001/jama.2020.1585

WHO (2017). World Health Organization Country Cooperation Strategy: At a GlanceEritrea. Geneva: World Health Organization.

WHO (2020). WHO Coronavirus Disease (COVID-19) Dashboard. Geneva: World 
Health Organization. https://covid19.who.int/table

World Bank (2018). Eritrea Overview: Context, Strategy, Results, Partners. Washington DC: The World Bank Group. https://www.worldbank.org./en/country/eritrea/overview

Yin, R. K. (2003). Case Study Research: Design and Methods (3rd ed.). Thousand Oaks, CA: Sage Publications. 